\title{
Tecnologias sociais de acesso à água enquanto estratégias de convivência com o semiárido: experiências e protagonismo da comunidade do Sítio Carcaré, São José da Lagoa Tapada-PB
}

\author{
Benedita Martins Tomaz ${ }^{1,2}$ (1) \& Hugo da Silva Florentino ${ }^{2,3}$ (D)
}

(1) Universidade Federal de Campina Grande, Centro de Formação de Professores, Unidade Acadêmica de Geografia, Rua Sérgio Moreira de Figueiredo, Casas Populares 58900-000, Cajazeiras, Paraíba, Brasil. E-mail: benedita.martins@ hotmail.com

(2) Universidade Federal de Campina Grande, Centro de Formação de Professores, Unidade Acadêmica de Ciências Exatas e da Natureza, Programa de Pós-Graduação em Meio Ambiente e Desenvolvimento no Semiárido, Rua Sérgio Moreira de Figueiredo, Casas Populares 58900-000, Cajazeiras, Paraíba, Brasil.

(3) Universidade Federal de Campina Grande, Centro de Formação de Professores, Unidade Acadêmica de Ciências Exatas e da Natureza, Rua Sérgio Moreira de Figueiredo, Casas Populares 58900-000, Cajazeiras, Paraíba, Brasil. E-mail: hugoxtr@hotmail.com

Tomaz B.M. \& Florentino H.S. (2021) Tecnologias sociais de acesso à água enquanto estratégias de convivência com o semiárido: experiências e protagonismo da comunidade do Sítio Carcaré, São José da Lagoa Tapada-PB. Pesquisa e Ensino em Ciências Exatas e da Natureza, 5: e1706.

http://dx.doi.org/10.29215/pecen.v5i0.1706

Editora acadêmica: Raimunda de Fátima Neves Coêlho. Recebido: 01 outubro 2020. Aceito: 17 abril 2021. Publicado: 22 maio 2021.

Resumo: Esta pesquisa objetivou refletir os avanços, dificuldades e desafios em uma comunidade rural no Sertão paraibano após a implantação de tecnologias sociais de acesso à água desenvolvidas e aplicadas pela Articulação do Semiárido. O trabalho apoiou-se na abordagem qualitativa, do tipo estudo de caso, cuja análise das experiências e dos resultados ocorreu por meio de entrevistas. Os resultados expõem que as cisternas de placas e de calçadão são tecnologias sociais de acesso à água que garantem as condições mínimas de água, promovendo inclusão e protagonismo das famílias, mas que ainda existem desafios de natureza política (quantidade de água e usos múltiplos, uso de carro-pipa em situações emergenciais e acesso à terra), estrutural (rachaduras e vazamentos por falta de manutenção), e de conhecimento para consolidação do paradigma da sustentabilidade e da convivência com o semiárido na área pesquisada.

Palavras chave: Políticas públicas, autonomia, ASA, cisternas.

Social technologies of access to water as strategies for living with the semiarid: experiences and protagonism of the community of Sítio Carcaré, São José da Lagoa Tapada-PB

Abstract: This research aimed to reflect the advances, difficulties and challenges in a rural community in the interior of Paraíba after the implementation of social technologies for access to water developed and applied by the Articulation of the Semiarid Region. The work is based on a qualitative approach, of the case study type, whose analysis of experiences and results occurred through alteration. The results explain that slab cisterns and sidewalk cisterns are social technologies for accessing water that guarantee minimum water conditions, promoting inclusion and the role of families, but that there are still political challenges (quantity of water and multiple uses, use of water tankers in emergency situations and access to land), structural (cracks and leaks due to lack of maintenance), and knowledge to consolidate the paradigm of sustainability and coexistence with the semiarid in the surveyed area.

Key words: Public policies, autonomy, ASA, cisterns. 


\section{Introdução}

O Semiárido Brasileiro (SAB) é uma região com cerca de $1.127 .953 \mathrm{Km}^{2}$ que ocupa uma parcela relevante da região Nordeste do Brasil. As condições climáticas típicas de clima semiárido provocam sérias limitações no modo de vida e nos processos produtivos da população (Pinto \& Lima 2008). Entretanto, as vulnerabilidades sociais, econômicas e ambientais encontradas no SAB não estão ligadas apenas às questões naturais e climáticas, mas, sobretudo, às situações de natureza política (Baptista \& Campos 2013a), que por meio de ações denominadas de "combate à seca" continuam a beneficiar e manter os privilégios das elites dominantes e a dependência do povo.

Em contrapartida, às políticas de combate à seca, surgem vários Programas voltados para a convivência com o Semiárido que foram e vêm sendo desenvolvidos na busca por alternativas que melhorem as condições de vida da população do campo e contribuam para sua fixação (Pinto \& Lima 2008), a exemplo do Programa de Formação e Mobilização Social para a Convivência com o Semi-Árido - Um Milhão de Cisternas Rurais (P1MC) e Uma Terra e Duas Águas (P1+2), ambos desenvolvidos pela Articulação do Semiárido (ASA), entidade criada em 1999. A título de contextualização, no estado da Paraíba, os programas P1MC e P1+2 já beneficiaram cerca de 89.138 famílias e no município de São José da Lagoa Tapada, onde a pesquisa foi realizada, cerca de 1.090 famílias (Asa 2019a) com água de qualidade para consumo e produção e, com isso, o desenvolvimento da autonomia, principalmente, nos períodos de estiagem e/ou seca.

Dada a importância da temática, a pesquisa buscou entender as seguintes questões: como as famílias conviviam antigamente com os períodos de estiagem, bem como os motivos aos quais levaram a comunidade a aderir ou não aos Programas P1MC e P1+2, identificando e avaliando as relações vivenciadas pela comunidade e seus desdobramentos para superação de práticas de combate à seca em direção à convivência com Semiárido, no exercício da cidadania e da construção da autonomia e empoderamento das famílias rurais no que tange a segurança hídrica, alimentar e nutricional, proporcionando melhorias na qualidade de vida no Semiárido.

Portanto, esta pesquisa teve por objetivo refletir sobre os avanços, dificuldades e desafios em uma comunidade rural no Sertão paraibano após a implantação de tecnologias sociais de acesso à água ${ }^{1}$ desenvolvidas e aplicadas pela ASA.

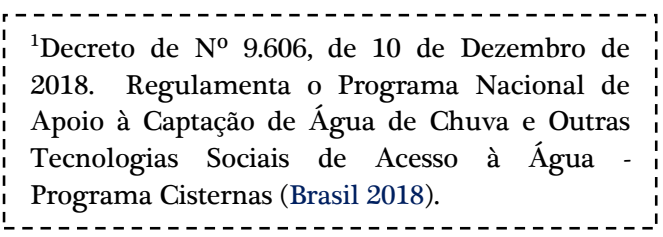

\section{Metodologia}

\section{Delimitação e caracterização da área de estudo}

A pesquisa foi realizada entre os meses de março e julho de 2019 na comunidade rural conhecida por Carcaré, localizada no município de São José da Lagoa Tapada - PB. A escolha da comunidade justificou-se por ser beneficiada pelos Programas P1MC e o P1+2, ambos desenvolvidos pela ASA; por estar inserida no SAB; e pela acessibilidade, uma vez que a comunidade fica próxima à sede do município.

Segundo o Instituto Brasileiro de Geografia e Estatística (IBGE 2017a), o município de São José da Lagoa Tapada pertence à Região Geográfica Intermediária de Sousa-Cajazeiras, e mais precisamente na Região Geográfica Imediata de Sousa. Com uma distância de aproximadamente $478 \mathrm{~km}$ da capital estadual, João Pessoa, o município tem uma área de 341.80 $\mathrm{km}^{2}$ e limita-se ao norte com Sousa e Aparecida, a oeste com Nazarezinho, ao sul com Aguiar, a Sudeste com Coremas e a Leste com São Domingos e Pombal (Figura 1).

Segundo o Censo do IBGE (2010), a população do município era de 7.564, sendo 3.315 pessoas morando na zona urbana e 4.249 pessoas morando na zona rural. O Índice de Desenvolvimento Humano (IDH) atingiu o valor de 0.530 , em 2010, colocando o município na 5.395 ${ }^{\mathrm{a}}$ posição em um ranking de 5.565 municípios brasileiros. Na Paraíba, o município ocupou, em 2010, a 214 a dos 223 municípios da Paraíba, que de acordo com o Programa das Nações 
Unidas para o Desenvolvimento (PNUD) é considerado como um município de baixo desenvolvimento humano (PNUD 2013).

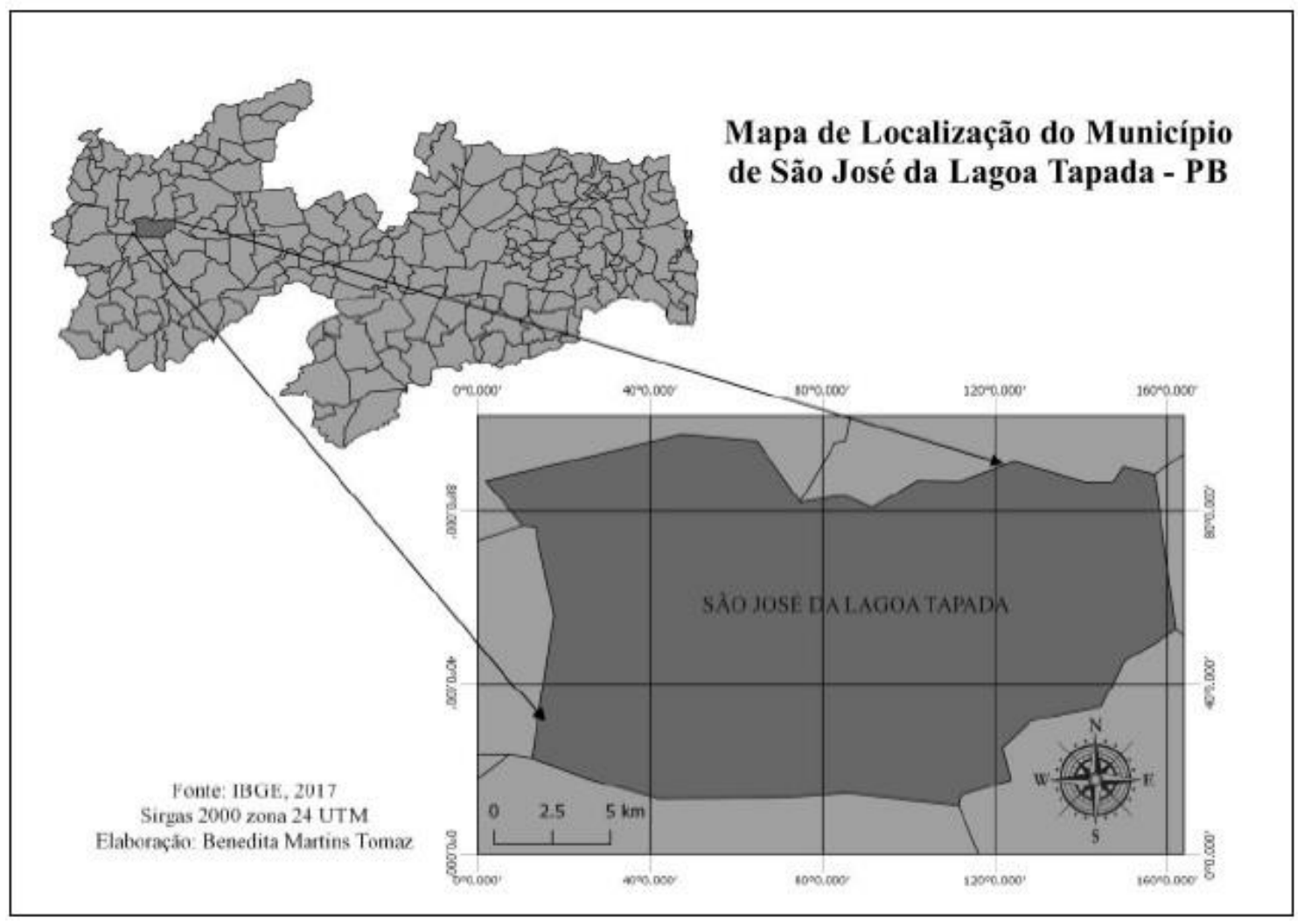

Figura 1. Mapa de localização do município de São José da Lagoa Tapada-PB. Fonte: Tomaz (2017).

Segundo o IBGE (2017b), o Produto Interno Bruto do município, em 2017, foi de R\$ 57.793.84 e a principal atividade econômica praticada no município era a agropecuária, seguido pelo o setor do comércio e a indústria de cerâmica. No ano de 2017, o setor agropecuário representou para o município cerca de $\mathrm{R} \$$ 5.072.46 (IBGE 2017c).

\section{Sujeitos da pesquisa}

Para entender o Programa pelo ponto de vista de seus usuários, foram escolhidas seis famílias de maneira intencional, sendo três famílias que participam do P1MC, duas que participam do $\mathrm{P} 1+2$ e uma que não participa de nenhum Programa, em um universo de 15 famílias, tomando como referência a amostragem direcionada, uma vez que tratou-se de uma pesquisa não censitária, como explica Lakatos \& Marconi (2010: 206): "não abrange a totalidade dos componentes do universo, surgindo a necessidade de investigar apenas uma parte dessa população".

O entrevistado 1, de gênero masculino, é o único integrante da família e representa a família que não aderiu a nenhum programa. $\mathrm{O}$ entrevistado 2 , de gênero feminino, possui três membros na família e representa a família beneficiada pelo programa $\mathrm{P} 1+2$. O entrevistado 3 , de gênero feminino, possui quatro membros na família e representa a família beneficiada pelo programa P1MC. O entrevistado 4, de gênero feminino, possui três membros na família e representa a família beneficiada pelo programa P1MC. O entrevistado 5, de gênero feminino, possui dois membros na família e representa a família beneficiada pelo programa $\mathrm{P} 1+2$. $\mathrm{O}$ entrevistado 6, de gênero feminino, possui três membros na família e representa a família beneficiada pelo programa P1MC. 


\section{Tipo de pesquisa}

Trata-se de um estudo de natureza qualitativa, que segundo Gerhardt \& Souza (2009), não se preocupa com representatividade numérica, mas, sim, com o aprofundamento da compreensão de um grupo social, de uma organização, ou seja, preocupa-se com aspectos da realidade que não podem ser quantificados, centrando-se na compreensão e explicação da dinâmica das relações sociais.

A pesquisa foi baseada, quanto aos procedimentos técnicos, em um estudo de caso que, segundo Gil (2008), é um estudo empírico que investiga um fenômeno atual dentro do seu contexto de realidade, quando as fronteiras entre o fenômeno e o contexto não são claramente definidas e no qual são utilizadas várias fontes de evidência.

\section{Instrumentos de coleta e tratamento de dados}

Utilizou-se como instrumentos de coleta de dados a observação e a entrevista fechada adaptada de Mota (2017), os quais forneceram informações sobre a realidade da comunidade em relação à implantação de tecnologias sociais pela ASA e, consequentemente, suas contribuições para convivência com o Semiárido. A observação contribuiu na visualização in loco dos avanços, desafios e obstáculos da implantação dos programas P1MC e P1+2 pela ASA.

A análise das experiências e dos resultados decorrentes dos usos de tecnologias sociais e práticas voltadas à convivência com o Semiárido estão fundamentadas nas pesquisas de natureza descritiva. Para Gil (2008: 28) "as pesquisas descritivas têm como objetivo primordial a descrição das características de determinada população ou fenômeno ou, então, o estabelecimento de relações entre variáveis".

\section{Aspectos Éticos}

A pesquisa proveniente deste estudo foi conduzida por meio de preceitos éticos que envolvem a Resolução No 466/2012 e 510/2016 do Conselho Nacional de Saúde e aprovada pelo Comitê de Ética em Pesquisa (CEP) do Centro de Formação de Professores (CFP), da Universidade Federal de Campina Grande (UFCG), sob o parecer n ${ }^{\circ}$ 07778819.2.0000.5575.

\section{Fundamentação teórica}

\section{O paradigma do combate à seca e o papel do estado no subdesenvolvimento do Semiárido}

O SAB é composto por 1.262 municípios, uma área que ocupa cerca de 1/5 (um quinto) do território nacional, situando sua maior parte na região Nordeste do país e estendendo-se até a parte setentrional de Minas Gerais (Figura 2) (Brasil 2017).

A região semiárida brasileira é a maior do mundo e a mais chuvosa. Silva et al (2010) caracteriza o quadro físico como baixo índice pluviométrico (precipitação anual máxima de 800 $\mathrm{mm} / \mathrm{ano}$ ), forte insolação, elevadas temperaturas (médias anuais de $23^{\circ}$ a $27^{\circ} \mathrm{C}$ ), precipitações irregulares e mal distribuídas no espaço/tempo e déficit hídrico, cujas taxas de evaporação chegam em média de 2.000 a $3.000 \mathrm{~mm} / \mathrm{ano}$. Além disso, outros fatores como dinâmica da massa de ar, relevo regional, o fenômeno climático conhecido por El Niño e proximidade com a linha do equador coloca o SAB como uma zona sujeita a períodos cíclicos de seca (Suassuna 2007).

Com uma população de 27.870.241 habitantes (INSA 2017), o SAB é um dos mais povoados do mundo e, em função das adversidades climáticas, associadas aos outros fatores históricos, geográficos e políticos que retomam centenas de anos, abriga a parcela mais pobre da população do país (Silva et al. 2010). Isso significa que o IDH dos municípios inseridos no Semiárido localiza-se entre os mais baixos do Brasil.

Devido as suas características edafoclimáticas, acreditou-se por muito tempo que o atraso econômico, as disparidades regionais e a "miséria" no SAB, que deflagra, principalmente, nos períodos prolongados de estiagem, eram reflexos das condições naturais e do clima da região (Silva 2003). 
A concepção do Semiárido, enquanto ambiente hostil e pobre, foi construída no imaginário popular devido a implementação das políticas de combate à seca e reforçada pelos meios de comunicação (literatura, dramaturgia, música e artes plásticas, do início do século XX); e, com isso, determinante para propagarem um cenário de um Semiárido pobre, improdutivo e de subdesenvolvimento, que já perpassam gerações (Silva 2003; Abílio 2011; Baptista 2011).

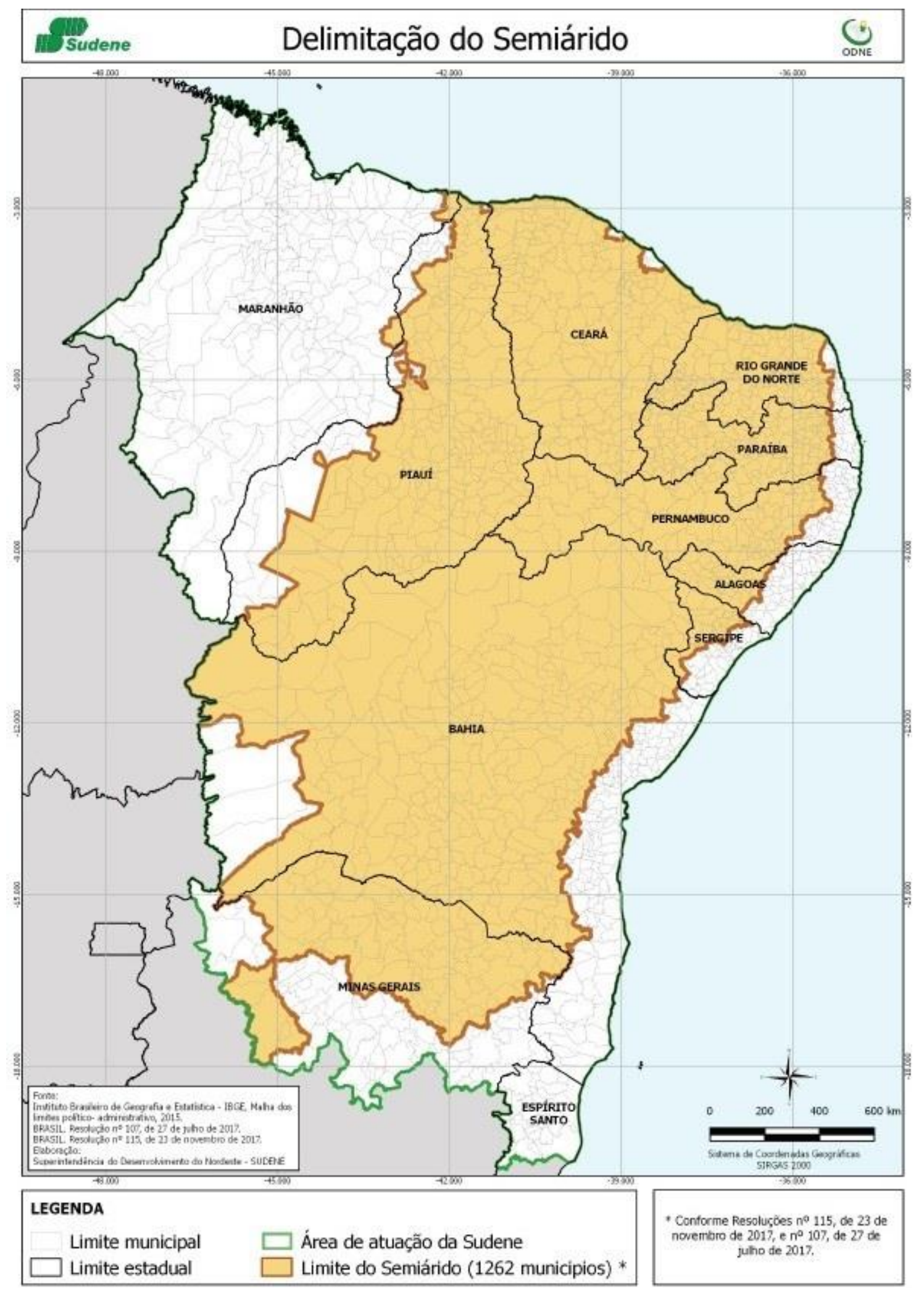

Figura 2. Mapa mostrando a delimitação do Semiárido. Fonte: SUDENE (2017). 
Como exposto, os problemas sociais vivenciados no $\mathrm{SAB}$ não estão ligados às questões naturais, mas, sobretudo, às questões políticas. Para Pereira (2013), terra, água e poder sempre estiveram concentrados nas mãos de uma pequena elite beneficiada por um longo período por políticas públicas denominadas de “combate à seca”.

As primeiras iniciativas para lidar com a seca no Nordeste ocorreram no século XX com a criação da Inspetoria de Obras Contra as Secas (IOCS), em 1909, transformado em Instituto Federal de Obras Contra as Secas (IFOCS) em 1919 e em Departamento Nacional de Obras Contra as Secas (DNOCS) em 1945 (Malvezzi 2016). Durante esse período, foram criadas as principais obras de infraestrutura hídrica do Nordeste, a exemplo da construção de açudes, barragens e projetos de irrigação, no geral, controlados pelos grandes proprietários de terra e classe política local; e, também, os projetos assistencialistas que auxiliavam os pobres durante os períodos de seca.

As estratégias adotadas, enquanto política de combate à seca, se estruturaram basicamente em duas fases ou momentos. No primeiro momento beneficiavam, em sua maioria, os grandes proprietários de terra e os empresários, mantendo e favorecendo a concentração de terra, da água. No segundo momento, gerava dependência do povo, através de doações, esmolas, carrospipa, frentes emergenciais, geralmente ligadas ao voto, e desenvolvidas apenas em momentos de "calamidade pública" que estimularam a prática de relações "clientelistas" e de submissão às elites locais (Silva 2003; Baptista 2011; Baptista \& Campos 2013b; Pereira 2013; Silva et al. 2016).

Entretanto, essas intervenções e investimentos executados pelo Estado, como supostos meios de solucionar o problema da falta de água, principal drama do sertanejo, se mostraram insuficientes e até mesmo ineficientes. Para Malvezzi (2016), ao analisar os dados do IDH do Semiárido, que continua sendo o mais "atrasado" do país, essas chamadas "reformas" e/ou "modernizações conservadoras", assim, como em sua origem, durante a ditadura militar, continuam a não chegar à população mais excluída e vulnerável aos efeitos da seca.

Problemas como fome, sede, migração e mortalidade, particularmente a infantil, continuam ocorrendo no Semiárido, sobretudo, onde políticas públicas de convivência não são fortalecidas e/ou implementadas, sendo as principais consequências das políticas estruturantes da denominada "indústria da seca", ou seja, "o paradigma de combate à seca resulta na manutenção da miséria. Funciona como uma estratégia perversa de manutenção e controle de uma região que, a princípio, e com raras exceções, não cabe na lógica do modelo de desenvolvimento que predomina” (Silva 2003: 12).

\section{A convivência com o Semiárido e as tecnologias sociais de acesso à água}

As políticas de combate à seca, adotadas desde o início do século XX, atualmente, estão em crise. Para Silva (2006), a ineficiência e descompasso com os princípios da sustentabilidade discutida, sobretudo no século XXI, vêm estabelecendo uma nova forma de pensar e intervir na realidade do Semiárido, que estrutura-se, basicamente, na crítica às políticas de combate à seca, no poder das classes dominantes e no modelo conservador de desenvolvimento estabelecido na região.

Historicamente, o processo de pensar o Semiárido sobre um viés da convivência, surge após a queda do regime militar, através da organização da sociedade civil, oriundos de igrejas, sindicatos, movimentos sociais e organizações não governamentais, sem excluir parcerias, apoios das Universidades, entre outros que, em um processo de convergências, vão formar novos atores sociopolíticos no Semiárido. Desses novos atores veio a proposta de outro paradigma, isto é, a “convivência com o Semiárido” (Baptista 2011; Malvezzi 2016).

O paradigma de convivência com o Semiárido, contudo, nasce sob uma nova forma de construir relações harmoniosas entre o ser humano e o ambiente, tendo em vista melhorar a qualidade de vida das famílias que vivem nessa região. Esta é uma forma de direcionar o olhar para os limites e potencialidades do Semiárido, retirando o sentimento de "culpa” atribuído às condições edafoclimáticas da região e inserindo novos elementos a esta abordagem (Silva 2006). Este paradigma exige uma visão sistêmica, de forma que todas as dimensões dessa realidade 
sejam abordadas, como reforça Malvezzi (2007: 9), ao dizer que "O Semi-Árido brasileiro não é apenas clima, vegetação, solo, sol ou água. É povo, música, festa, arte, religião, política, história. É processo social. Não se pode compreendê-lo de um ângulo só”.

Segundo Malvezzi (2016), dentro da perspectiva de convivência com o semiárido, destacam-se as tecnologias sociais que podem ser consideradas como:

\footnotetext{
[...] técnicas, materiais e procedimentos metodológicos testados, validados e com impacto social comprovado, criados a partir de necessidades sociais, com o fim de solucionar um problema social. Uma tecnologia social sempre considera as realidades sociais locais e está, de forma geral, associada a formas de organização coletiva, representando soluções para a inclusão social e melhoria da qualidade de vida (Baumgarten 2008: 114).
}

As tecnologias sociais diferem das obras de combate à seca ao permitir autonomia e empoderamento do povo. Tais tecnologias são de baixo custo, simples e com efeitos positivos para geração de renda, saúde, emprego, produção de alimentos, nutrição, habitação, relações sociais e para o meio ambiente. Por meio das tecnologias sociais, é possível promover a inclusão social e o protagonismo, podendo ser facilmente reaplicáveis e controladas pela população, já que preveem a incorporação de práticas sustentáveis a partir de conhecimentos locais a fim de resolver problemas nas comunidades (Ventura et al. 2014). Malvezzi (2007) afirma que a materialização da convivência representou um (re) aprendizado sobre a sabedoria popular e o resgate de tecnologias que já haviam sido desenvolvidas.

Vale ressaltar que desde o início da articulação das organizações atuantes no Semiárido, a falta de acesso à água é debatida como questão crítica a ser resolvida. Malvezzi (2007) explica que no Semiárido as tecnologias sociais dizem respeito, sobretudo, à questão hídrica. O que está em jogo é o aproveitamento máximo da água disponível e sua estocagem para os períodos em que ela faltará, promovendo uma segurança hídrica para períodos críticos. É a cultura da "previdência", em vez da "providência".

Em suma, a principal estratégia adotada para auxiliar a população a conviver com o Semiárido consiste em ações de educação e implantação de tecnologias sociais de captação e armazenamento de águas pluviais. Dentre estas, destaca-se, desde 2003, o P1MC e P1+2, que através de técnicas simples, de fácil acesso e com processos educativos, os Programas desenvolvem um conjunto de tecnologias sociais de captação e armazenamento da água da chuva para consumo humano e produção, construída ao redor da casa para garantir a autonomia e gerenciamento da água, direito essencial à vida e à cidadania.

\section{Programa de formação e mobilização social para a convivência com o Semiárido: P1MC e P1+2}

O Programa de Formação e Mobilização Social para a Convivência com o Semiárido é um sistema simplificado de aproveitamento de água de chuva, por meio da construção de cisternas, e com gestão sustentada na participação da sociedade civil organizada. Idealizado em 2001 pela ASA, o Programa contou com o apoio do Governo Federal, sendo incorporado no ano de 2003 ao Programa governamental Fome Zero, institucionalizando-se sob a responsabilidade do Ministério do Desenvolvimento Social e Combate à Fome (MDS) (Gomes \& Heller 2016). Integram ao Programa de Formação e Mobilização Social para a Convivência com o Semiárido os Programas "um Milhão de Cisternas Rurais" (P1MC) e "uma Terra e duas Águas" (P1+2).

O P1MC foi criado em 2003 com o anseio de melhorar a vida das famílias que vivem na região semiárida do Brasil, tendo como principal objetivo o acesso à água de qualidade (Asa 2019b). A cisterna de Placa do Programa P1MC, tem capacidade para 16 mil litros e, se usado para beber, cozinhar e escovar os dentes é volume suficiente para abastecer uma família de até seis pessoas durante período de estiagem que pode chegar a oito meses (Figura 3). O seu funcionamento prevê a captação de água da chuva que cai no telhado da casa e escoa para a cisterna através das calhas. Além disso, este Programa proporciona às famílias formação social e mobilização que possibilita a compreensão de como conviver adequadamente com a semiaridez 
e, principalmente, o entendimento de que a água é um direito e a cisterna é uma conquista da família.

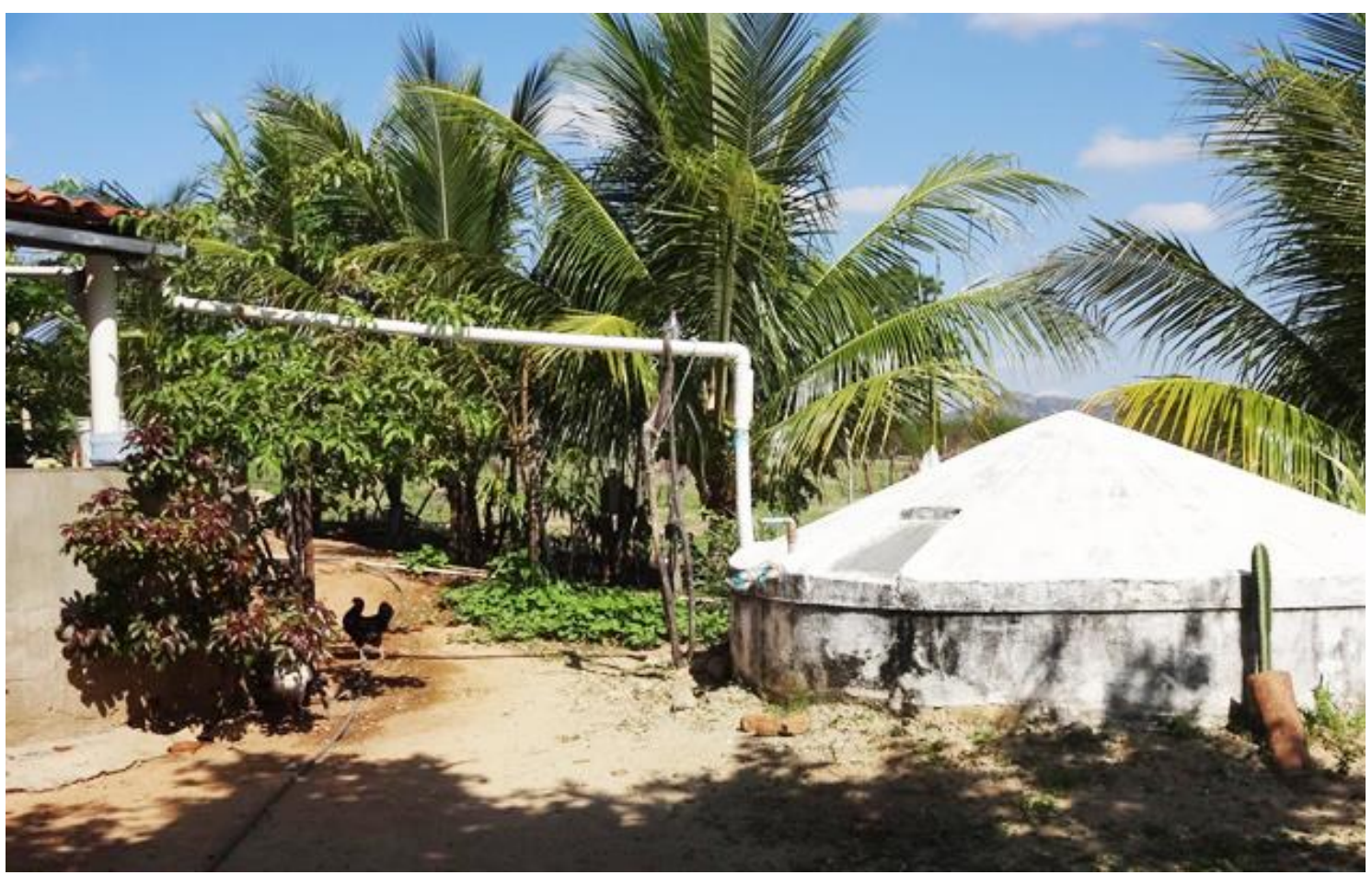

Figura 3. Cisterna de placa do P1MC. Foto: Bendita Martins.

No ano de 2007, com o intuito de ampliar o estoque de água destinada ao plantio e criação de animais, a ASA criou o P1 +2 . Seu objetivo foi promover a segurança alimentar e nutricional das famílias de agricultores e fomentar a geração de emprego e renda para as mesmas (Asa 2019c). Para fazer parte do P1+2, a família deve possuir uma cisterna de placa para consumo humano, ou seja, a família precisa fazer parte do P1MC.

As tecnologias que captam e guardam água da chuva para produção de alimentos levam em consideração as características do local onde vão ser implementadas e a sua interação com a estratégia utilizada pela família para produzir. Atualmente, o Programa trabalha com as seguintes tecnologias: cisternas calçadão de 52 mil litros de água (Figura 4), cisterna de enxurrada de 52 mil litros, barragem subterrânea, tanques de pedras, instalação de bombas populares, barreiros-trincheiras e barraginhas. A água captada deve ser utilizada para irrigar quintais produtivos: plantas, fruteiras, hortaliças, plantas medicinais e para criação de animais.

Para participar dos Programas supracitados são selecionadas as comunidades e famílias que estejam inscritas no Cadastro Único (CadÚnico) para programas sociais. Entre os critérios estabelecidos, estão: a mulher como chefe de família; família de baixa renda; família com crianças de 0 a 6 anos; famílias com crianças e adolescentes frequentando a escola; adultos com idade igual ou superior a 65 anos; deficientes físicos e/ou mentais; e a família residente na zona rural sem acesso à água encanada em quantidade e qualidade suficientes para o consumo humano e para produção de alimentos e criação de animais.

Após o processo de seleção das famílias, a outra etapa consistiu em participarem do Curso de Gerenciamento de Recursos Hídricos (GRH), o qual abordou questões relacionadas ao Semiárido, aos cuidados com a cisterna e com a água. Outras capacitações realizadas se constituíram em processos de formação de diferentes atores que participaram do Programa, entre eles: as famílias, as comissões municipais e pedreiros e pedreiras que construíram as cisternas (Asa 2019b). 


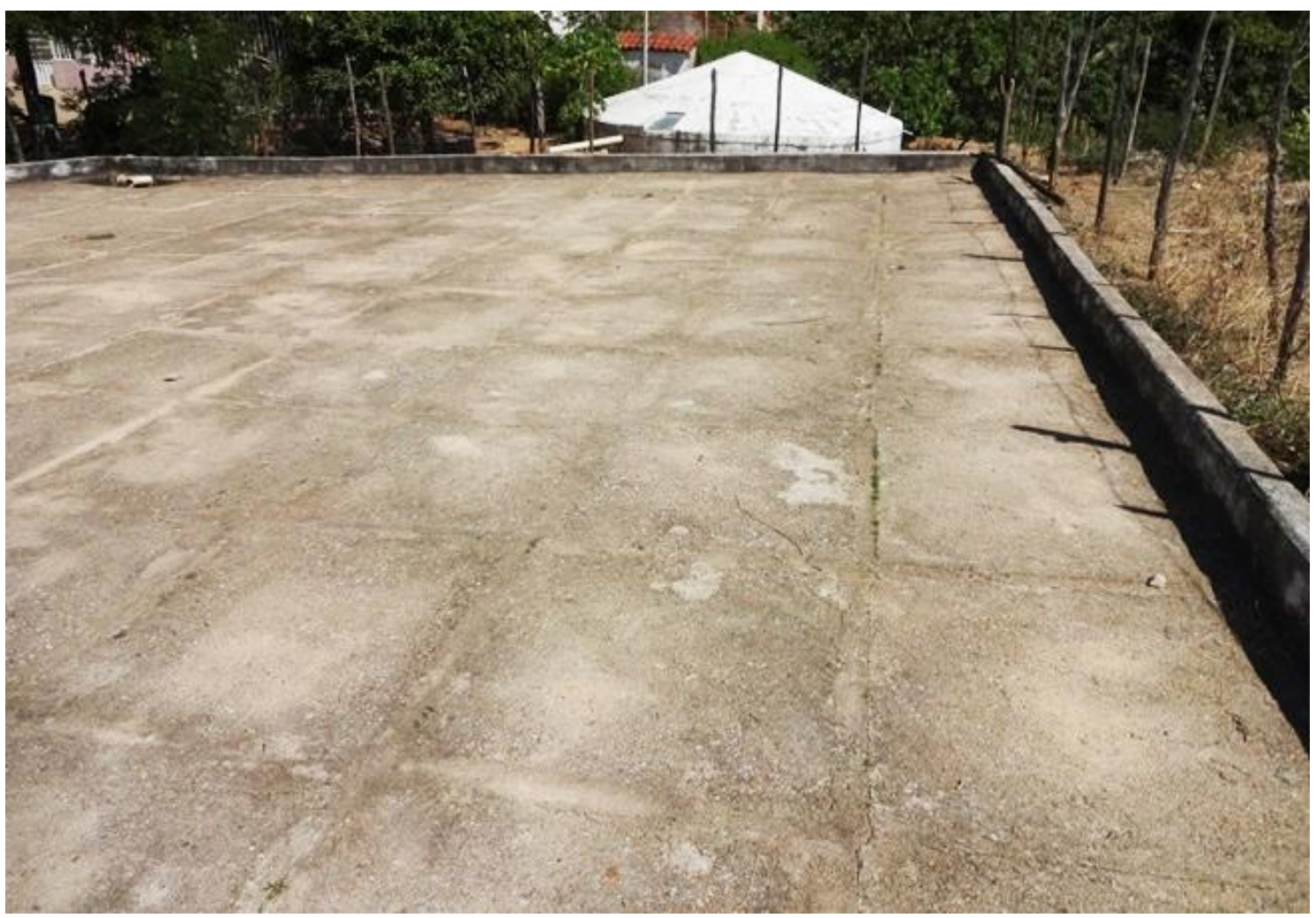

Figura 4. Cisterna de calçadão do P1+2. Foto: Benedita Martins.

Podemos dizer que as cisternas representam o "principal exemplo de como é possível atender à demanda hídrica familiar, pelo menos sob o ponto de vista da saúde a da segurança alimentar e nutricional, combinando elementos de participação social, atuação do poder público e emancipação das famílias" (Arsky et al. 2013: 142).

Infelizmente, desde a sua implantação, o Programa vem sofrendo reduções de recursos ano a ano (Melito 2020). Na Lei Orçamentária Anual (LOA) para 2020, o montante financeiro previsto para o Programa Cisternas foi o mais baixo desde a sua criação. A projeção para o Plano Plurianual (PPA 2020-2023) representa menos da metade dos recursos previstos no orçamento apenas para 2014, quando iniciou a redução orçamentária para o Programa de Cisternas. A coordenadora executiva da ASA, em Minas gerais, Valquíria Lima apud Melito (2020) alertou que a redução de recursos destinada à construção de cisternas representa um retrocesso às políticas de convivência, sinalizando o retorno progressivo da fome em áreas vulneráveis no Semiárido.

\section{Resultados e Discussão}

A perspectiva de convivência com o Semiárido requer que as políticas públicas destinadas para esta região sejam apropriadas para a realidade e, para que isso ocorra, o primeiro passo é reconhecer os sujeitos como protagonistas sociais de todo o processo. Para isso, é importante entender e diferenciar políticas governamentais que fundamentam o discurso do combate à seca, das políticas públicas de convivência com o Semiárido (Silva et al. 2013).

As políticas governamentais, elaboradas por técnicos do Estado, são as ações que não consideram a participação do público ou contexto no qual serão efetivadas; são os projetos de exclusão que Baptista (2016: 31) caracterizou como "movimento exógeno que parte dos supostos limites, todos comparados de fora para dentro e propõe a "artificialização" da região, não considerando as estratégias e conhecimentos construídos localmente". Este modo de pensar o Semiárido resultou nas estratégias de "combate à seca", que se mostraram pouco eficientes. 
No entendimento do questionamento levantado anteriormente, questionou-se como as famílias conviveram com os períodos de estiagem antes das chegadas das cisternas, e os mesmos relataram da seguinte forma:

\begin{abstract}
"Era bem difícil, porque antes não tinha os benefícios que hoje tem. Antes a gente tinha que ir lá pro açude do governo, a pé, carregando na cabeça, todo o santo dia. Antigamente não tinha cacimbão, nem açude perto. $E$ a gente tinha que ficar esperando pela chuva" (Entrevistado 2: $\mathrm{P} 1+2$ ).
\end{abstract}

"Era sofrimento. A gente nunca teve água perto. Tinha que ir buscar no jumento, carregando água, buscando longe. Dava uns 1.000 metros daqui pro açude do governo, que era onde a gente pegava a água. E essa tarefa ficava mais pra mulher. Era eu que tinha que ir buscar [água] pra meu marido poder ir trabalhar na roça"(Entrevistado 3: P1MC).

"Era tudo muito difícil. A gente ia buscar água a mais de 500 metros de distância, e às vezes a gente ia buscar água e não tinha água, a gente voltava com a lata seca. Era um sofrimento. Sofremos muito com a falta de água. A gente ia lavar roupa lá no açude do governo, tudo de pé. Não tinha ajuda do governo e quando tinha as emergências do governo era muito difícil de consegui" (Entrevistado 5: P1+2).

A partir da percepção das famílias com relação às ações de combate à seca, notou-se a ineficiência e degradação das condições sociais da população do Sítio Carcaré. Pelos relatos, as famílias necessitavam realizar deslocamentos de longas distâncias diariamente, a pé ou transportados por animais para encontrar algum açude que disponibilizasse a água, péssima para a saúde humana. Os períodos de sofrimentos e dificuldades relatados pelos entrevistados retratam o período em que a solução imposta pelo governo para resolver o problema da estiagem estava pautado na construção de grandes reservatórios de água - açude do governo, como eles denominaram -, e no assistencialismo sazonal.

As políticas de "açudagem", enraizadas na memória dos entrevistados, fazem parte de uma época que se acreditava que os problemas sociais do Semiárido estavam relacionados apenas aos fatores climáticos (Silva et al. 2016). Este discurso alimentou o paradigma de "combate à seca" e a "indústria da seca", ambos determinantes para gerar dependência, tanto política quanto econômica, dos grupos dominantes da época.

Entretanto, as políticas públicas de convivência com o Semiárido que Baptista (2016: 31) chamou de projetos de inclusão, são "um movimento endógeno, construído na luta diária de mulheres e homens em distintas fases de suas vidas, os quais são portadores de um vasto saber adquirido a partir da observação da natureza ao longo dos tempos”. Em outras palavras, são as ações construídas a partir da participação e diálogo com aqueles que serão beneficiados; são elaboradas a partir do protagonismo de homens e mulheres na luta por melhorias da qualidade de vida no Semiárido.

Segundo Silva et al. (2013), as políticas de convivência com o Semiárido começaram a ser implementadas quando o Estado fez parceria com a sociedade civil. Com isso, através da ASA, passou-se a estabelecer políticas públicas que valorizassem as tecnologias sociais e o empoderamento das famílias que vivem e convivem com o Semiárido e, consequentemente, passando a não ser mais uma ação assistencialista de propagação das condições de dependência, mas um movimento que oportuniza a comunidade a participar das ações de forma coletiva, que mudam a realidade da região e, sobretudo, transformam as condições de vida e a relação da população do campo com o ambiente.

Nesse sentido, entre as políticas públicas de convivência com o Semiárido, destaca-se as iniciativas que envolvem a estocagem de água em tempo chuvoso para viver adequadamente no tempo de escassez. Tendo em vista que o problema maior da região não é a falta de água, mas o acesso a ela, as tecnologias sociais de acesso à água, a exemplo da implantação de cisternas, que chegaram à comunidade por meio do P1MC e P1+2 pela ASA, em 2003 e 2011, respectivamente, 
com o objetivo de garantir o acesso e a democratização da água para consumo humano e para a produção.

Considerando que a tecnologia social de acesso à água mais difundida na comunidade foi a cisterna de placa, questionou-se quais as contribuições ou mudanças que essa tecnologia trouxe para a comunidade. Percebe-se, portanto, uma satisfação das famílias em relação às cisternas principalmente por proporcionar água perto de suas residências, conforme depoimentos dos participantes da pesquisa:

"Ela só trouxe coisa boa. Ajudou a gente plantar, porque antes não tinha como
plantar. Não precisa mais ir para longe buscar água. Temos água perto de casa e água com qualidade, pra cozinhar, plantar, beber"(Entrevistado 2: $\mathrm{P} 1+2$ ).

"Muitas. Para gente foi ótimo, porque antigamente a gente tinha que amanhecer o dia pra ir buscar a água e arrumar tempo ainda pra levar os meninos pra escola, cuidar da casa. Agora com a água pertinho da gente é uma maravilha. Facilitou nossa vida. A gente tem muito a agradecer a quem inventou ela" (Entrevistado 3: P1MC).

"Saímos do sufoco. Foi um alívio. Agora a gente tem onde guardar a água da chuva e não precisa tá caminhando léguas de distância em busca d'água" (Entrevistado 5: P1+2).

Comparando a percepção dos moradores antes e depois das cisternas, ficou evidente em seus depoimentos o quanto foi satisfatório e significativo as contribuições que as cisternas trouxeram para eles. Informações como estas também foram relatadas nos estudos de Oliveira (2013), realizado em uma área que abrangeu as cidades de Desterro - PB, Cacimbas - PB, Teixeira - PB, Taperoá - PB, Livramento - PB, Olivedos - PB, Pocinho - PB e Soledade - PB; em Calixto Junior \& Silva (2016) na comunidade do Sítio Faustino, Crato - CE; em Silva et al. (2016) no assentamento Serra do Monte, situado no município de Cabaceiras - PB; em Mota (2017) numa comunidade rural de Riacho da Arara, Cajazeiras - PB; e em Alencar et al. (2018), Jardim $-\mathrm{CE}$.

Outra importância relatada foi o impacto das cisternas sobre a organização social das mulheres. Considerada extensão do trabalho doméstico, a mulher - mãe, esposa e dona de casa -, era submetida a buscar a água enquanto o homem cuidava da roça. Esta cena, descrita na fala do entrevistado 3, representa o sofrimento das mulheres, que precisavam conciliar as jornadas de trabalho doméstico com as longas caminhadas até açudes, barreiros ou outras fontes para o abastecimento de água da casa, que muitas vezes supõe seu deslocamento diário e esforço físico.

Segundo Malvezzi (2007), a cisterna proporcionou "um alívio do trabalho feminino", gerando conforto, saúde e mais tempo para trabalhar, estudar e cuidar da casa, da família e da vida em geral. Sem dúvida, a possibilidade de ter água na porta de casa é entendida como a melhor das finalidades da cisterna.

Embora o principal objetivo do Programa seja a captação e o armazenamento da água da chuva, sua implantação representou importantes conquistas, dentre os quais destacam-se: o desaparecimento de doenças veiculadas na água contaminada; redução da mortalidade infantil; as dificuldades de deslocamento das pessoas; economia de tempo; aumento da frequência escolar; segurança alimentar e nutricional, e principalmente, promoveu a independência, liberdade e autonomia para gerenciar seu recurso conforme achar melhor (Malvezzi 2007).

Além disso, os processos que acompanharam a implantação das cisternas conscientizaram as famílias que esses benefícios representam uma conquista e uma relação de pertencimento/domínio, de algo que agora é propriedade deles. Não é uma simples doação, favor ou presente (Alves 2013). Porém, o fato de os entrevistados não relatarem ou não perceberem determinados benefícios das cisternas, além de proporcionar água perto de casa, sugere que alguns caminhos precisam ser percorridos para que possam auxiliar no contexto da convivência. Mais que um reservatório de água, as cisternas precisam ser reconhecidas como um valioso 
mecanismo de mobilização social numa região tão carente de motivação e esperança de vida melhor.

Os cuidados e manejos são importantes como forma de garantir a qualidade da água. Para isso, o programa oferece capacitações que são movimentos direcionados à formação dos diversos atores que participam do programa - família, comissões municipais e pedreiros. As capacitações abordam questões como convivência, gerenciamento dos recursos hídricos (GRH) e cidadania, estimulando o protagonismo das famílias, desde o processo de aquisição, construção e cuidados com as cisternas. A ASA entende que essa é uma maneira das famílias se sentirem inseridas e darem mais valor ao benefício (Alves 2013).

Entre as questões discutidas nas capacitações estão os cuidados corretos e a higienização das cisternas, de forma a garantir a qualidade da água, principalmente para o consumo humano e a melhor forma de aproveitá-la nas atividades do cotidiano. Percebe-se o reflexo dessa ação quando questionou-se como as famílias manejam suas cisternas, cuja resposta está expressa no depoimento a seguir:

\begin{abstract}
"Na capacitação eu aprendi que não pode misturar a água da cisterna com outra água, e teve um ano que não deu pra encher e a gente teve que usar a água do açude, que vem na pipa $^{2}$, e quando começou a chuva meu marido misturou as duas águas. Com o tempo começou a criar "lodo" ai tivemos que esvaziar. Agora a gente só deixa entrar água da chuva. A gente tira a água na bomba ${ }^{3}$. Não pode colocar balde dentro. Todo ano a gente pinta com cal e sempre que ela está quase vazia, a gente lava ela"(Entrevistado 3: P1MC).
\end{abstract}

A higiene, o manuseio da água e a conservação das cisternas são práticas cotidianas que incentivam a autonomia, participação e autogestão, primícias do conceito de tecnologia social e da convivência. Conforme observado na fala do entrevistado 3, a ação de misturar a água da chuva com águas de outra origem permitiu a reflexão, a partir de sua prática, da importância do conhecimento adquirido no processo de formação proposto pelo programa, que orienta o uso exclusivo da água da chuva para garantir a qualidade da água para o consumo. Este processo de ação e reflexão permite uma interação do indivíduo com a tecnologia, valorizando o processo de inclusão social (Jesus \& Costa 2013).

Entretanto, existem os desafios e limitações que podem colocar em risco o sucesso e a

${ }^{2} \mathrm{O}$ entrevistado ao mencionar "pipa" estava referindo-se ao popularmente conhecido CarroPipa, caminhão com um grande reservatório usado para transportar água. $\mathrm{O}$ carro-pipa opera no semiárido por meio do Projeto Operação Carro Pipa do Exército, que fornece a água proveniente de açudes no período de estiagem, quando as cisternas estão secas.

${ }^{3}$ Neste caso, a bomba referida pelo o entrevistado é a bomba manual instalada junto a todas as cisternas para retirada da água. A bomba de acionamento manual é ligada diretamente na cisterna, sendo constituída de uma alavanca externa e uma mangueira interna que, quando acionada a alavanca, ocorre o bombeamento e a água é jorrada. Desta forma não é necessário utilizar baldes ou vasilhas para retirar à água, evitando o contato direto do utensílio com água e consequentemente sua possível contaminação. viabilidade do Programa. Além da questão da manutenção, outro ponto importante refere-se à finalidade da água e a eficiência da cisterna para atender as necessidades básicas, cujos entrevistados relataram da seguinte forma:

"A gente utiliza só para beber e cozinhar, e para as outras coisas a gente usa a água do poço. Se for só para beber, [a água] é suficiente sim. Nessa seca de agora a gente ajudou várias pessoas da família da gente que mora na cidade, que vinha buscar água também só pra beber. Agora se for fazer outras coisas, como tomar banho, lavar roupa, numa seca como essa, não da não. Pra essas outras coisas a gente usa a água do poço. Essa água da cisterna dá pra gente passar três anos, sem mudar o gosto"(Entrevistado 3: P1MC).

"A água é suficiente e ainda sobra de um ano para o outro, mas para o tanto que eu planto. Se for expandir a plantação não dá. Já a cisterna de placa se for só para beber e cozinha também é suficiente, mas para as outras atividades de casa a gente tem que usar a água do poço, que é salgada, que acaba com os canos, torneiras e o piso da casa"(Entrevistado 5: $\mathrm{P} 1+2$ ). 
"Eu utilizo para cozinhar, beber, às vezes tomar banho, lavar a casa, lavar a louça. Por isso eu tive que fazer o cadastro e uma vez por mês o carro-pipa vem colocar água nela”(Entrevistado 6: $\mathrm{P} 1 \mathrm{MG}$ ).

Com a finalidade de identificar se a água das cisternas era suficiente para atender as famílias durante o período de estiagem, questionou-se a quantidade de pessoas existente na residência. Segundo as informações obtidas, todos os entrevistados possuem menos de seis pessoas, o que torna os valores estipulados pela ASA adequado para a quantidade de água armazenada nas cisternas de placa $^{4}$, principalmente para as

${ }^{4}$ De acordo com os parâmetros da demanda hídrica apresentados no estudo de Arsky \& Santana (2013), a cisterna de placa de 16 mil litros é suficiente para garantir autonomia da família, considerando o uso da água para beber e para alguns usos domésticos como cozinhar, realizar sua higiene mínima, como lavar o rosto, as mãos e escovar os dentes durante o período de estiagem de cerca de 8 meses.

famílias que fazem o devido uso da cisterna. Para os beneficiados pelas cisternas de calçadão, os entrevistados relataram ser suficiente para a quantidade que atualmente produzem, mas, caso precisem expandir a produção será necessário aumentar a quantidade de água armazenada.

Verificou-se que há casos em que a quantidade de água da cisterna de placa não atende à demanda familiar, como ocorrido na família do entrevistado 6. Evidentemente que a água da cisterna, quando utilizada para outras finalidades não idealizadas pelo Programa (tomar banho, lavar a roupa e limpar a casa), secará antes do previsto, necessitando a família recorrer a carrospipas, como relata o entrevistado 6, o que acaba comprometendo a qualidade da água e saúde de quem a consome.

Embora a disponibilidade de água para beber é diferente do atendimento da demanda para os demais usos cotidiano da água, para a produção de alimentos em quintal ou para a criação de animais, é importante avaliar esse acesso a água sob a perspectiva da autonomia da família e com base em seus múltiplos usos, bem como de acordo com o contexto social, cultural e ambiental utilizando-se de todas as fontes de águas disponíveis (superficiais e subterrânea) e não apenas pluviais como forma de garantir quantidade suficiente de água para a família.

Com relação ao $\mathrm{P} 1+2$, a tecnologia social identificada com predominância é a cisterna de calçadão. Quando questionados sobre o que produzem com a água da cisterna de calçadão e se a produção é apenas para consumo próprio e/ou comercializam o excedente, os entrevistados 2 e 5 relataram que:

“A cisterna de calçadão é só para plantar hortaliças. A gente consome e vende
para os mercados, mas é mais para o consumo mesmo"(Entrevistado 2: $\mathrm{P} 1+2)$.

"Plantar hortaliça, plantas medicinais e uns pezinhos de limão e acerola e para a criação de porco e galinha, apenas para o consumo da minha casa e para meus parentes. Eu não vendo"(Entrevistado 5: P1+2).

As tecnologias sociais de acesso à água no Semiárido, a exemplo da cisterna de calçadão, além de garantir a segurança hídrica, quando aliada a outras políticas públicas ${ }^{5}$ do governo, como o Programa Nacional de Apoio à Agricultura Familiar (PRONAF), Programa de Aquisição de ${ }^{5}$ Não houve identificação de qualquer ligação
dos entrevistados com alguma política pública
de apoio a agricultura familiar do governo, a
exceção das cisternas de calçadão, estando essas
informações apenas de caráter complementar. Alimentos (PAA) e o Programa Nacional de Alimentação Escolar (PNAE), garantem a segurança alimentar, através do fortalecimento da agricultura familiar, sobretudo, em áreas consideradas relativamente carentes, do ponto de vista econômico. "Os resultados destas inovações se expressam na vida do povo do Semiárido através de mudanças na paisagem local, com nichos de produção ao redor de casa para o consumo da família e na resiliência aos efeitos das secas periódicas da região” (Rocha 2013: 115).

Estimular a agricultura familiar é uma forma de fixar os homens e as mulheres no campo, reduzindo o êxodo rural e promover a cidadania das famílias beneficiadas, uma vez que 
ao utilizarem as tecnologias sociais para práticas agrícolas, garantem segurança alimentar e nutricional e, em alguns casos, uma renda extra, fruto do seu trabalho e superior a qualquer outro programa assistencial do governo (Malvezzi 2007).

Existem também aqueles que por motivos diversos não aderiram ao Programa. No caso do entrevistado 1 explica que o motivo para não aceitar a cisterna foi: "não tenho aonde fazer. Não tenho terreno" (Entrevistado 1: Sem cisterna). Quando questionado sobre como ele enfrenta os períodos de estiagem, o mesmo relatou:

\begin{abstract}
"Vem água do açude de são Gonçalo para cisternas e eu uso a água da cisterna do meu irmão. É de lá que eu tiro a água para beber, cozinhar, e as outras obrigações da casa. Pra roça que tenho aqui em casa eu dependo da água do inverno. Também não tenho açude e nem poço"(Entrevistado 1: Sem cisterna).
\end{abstract}

Por falta de espaço, o entrevistado 1 foi obrigado a recusar o Programa. Embora não seja objetivo deste artigo discutir as estratégias sociais de acesso à terra, é importante destacar que a realidade das comunidades atendidas pelos Programas de Acesso a água da ASA não pode estar dissociada da dimensão fundiária ${ }^{6}$, uma vez que o tamanho da propriedade é um preceito importante para a autonomia das famílias e fortalecimento da convivência com o Semiárido, ou manutenção da condição de dependência e subserviência das comunidades às elites econômicas e políticas locais.

Para desafios como este, o $\mathrm{P} 1+2$ tem grande potencial para atuar rumo a essa proposta, visto que um dos objetivos é disponibilizar uma área de terra suficiente para as famílias viverem com dignidade, e para isso, o programa pressupõe, além das obras de acesso à água para captação de água da chuva, que ocorra uma reforma agrária, assim como na China ${ }^{7}$.

${ }^{6}$ Para além da água, a concentração fundiária no semiárido é histórica e política. Os latifúndios improdutivos, os grandes projetos do agronegócio, as grandes e tradicionais fazendas de gado tem reforçado essa injusta estrutura fundiária. Muitos agricultores e agricultoras ainda trabalham em terras alheias ou em minifúndios, superexplorados e com terras em péssimas condições de produção (Baptista \& Campos 2013a).

7“O $\mathrm{P} 1+2$ se inspira nas realizações do governo chinês no Semiárido daquele país, conhecido por " $1+2+1$ ". O projeto chinês consistiu em reforma agrária que deu a cada família 0.6 hectare de terra, um reservatório de captação de água de chuva no pé da casa para consumo humano, um reservatório na terra para captação de água de chuva para produção e uma área de captação da água para o reservatório de produção" (Malvezzi 2007: 124).

Ainda que as cisternas sejam de cada família, o manejo e gestão de suas águas pode ter um caráter coletivo, como é o caso do entrevistado 1 que utiliza a água da cisterna de seu irmão e do entrevistado 3, que disponibilizou a seus familiares residentes da cidade. Estes exemplos contribuem para propagação de relações de cooperação e solidariedade, sentimentos despertados pela identificação em relação ao sofrimento do outro; são ações que constroem valores sociais e que podem ser adotadas como exemplos para as demais famílias da comunidade.

Embora o estudo não contemple todas as famílias da comunidade, no decorrer das observações, foi identificado problemas estruturais em uma cisterna de placa e uma cisterna de calçadão relacionada a rachaduras e vazamentos, também relatados no estudo de Oliveira (2013). Segundo o autor, vários são os motivos que podem levar a cisterna a rachar, no entanto, o mais comum é a variação de temperatura no Semiárido e a má localização.

As rachaduras são problemas recorrentes e fáceis de ser reparados, no entanto, pela falta de assistência do Programa, as cisternas perderam seu objetivo de democratização de acesso à água, fazendo com que as famílias desviem a função das tecnologias ou retornem as práticas de combate à seca - a destacar a situação de uma família que transformou a cisterna de placa em um criatório de peixe e a beneficiária de uma cisterna calçadão, que abandonou o sistema por não conseguir repará-lo.

Para esse problema, é interessante refletir sobre a possibilidade de o Programa levar em consideração as condições geológicas do terreno, e quando ocorrer avarias em virtude do tempo e da temperatura, a realização de manutenções estruturais. Caso o problema persista, que a família possa receber uma nova cisterna. 
A questão da água no Semiárido é um dos pontos mais importantes para convivência, e as cisternas de placa representam um marco na segurança e soberania hídrica no SAB, embora a demanda por água para os demais usos domésticos, como tomar banho e lavar roupa, ainda exija a utilização de outras fontes de água. Se por um lado os programas da ASA garantem as condições mínimas de água para as famílias, reduzindo a dependência de açudes, poços artesianos, caixa d'água e carros-pipas, por outro reforça o papel dos mesmos para os demais usos domésticos da água. Isso significa que apesar dos avanços, a comunidade não está totalmente "livre" das práticas consideradas de combate à seca.

Malvezzi (2012) explica que existe um caminho longo a ser percorrido no Semiárido para que a população tenha uma infraestrutura adequada para enfrentar as situações de seca, entretanto, programas sociais como da ASA constituem em admiráveis avanços na perspectiva da convivência. $\mathrm{O}$ importante é que os primeiros passos estão ocorrendo e seus reflexos sentidos em praticamente todo o SAB.

Por esses motivos e pela necessidade, em alguns casos, de reabastecer as cisternas com água do carro-pipa, podem ser desenvolvidas como estratégia para comunidade as práticas de estoque de água: "Água para as comunidades e Água para emergências" (Baptista 2016). O objetivo é que tecnologias sociais de acesso à água, a destacar a cisterna de calçadão, a de enxurrada e a bomba d'água popular (BAP), possam ser construídas para o coletivo, ampliando a oferta de água para seus múltiplos usos; para períodos mais críticos; para famílias com mais de seis pessoas; famílias com problemas estruturais na cisterna; para quem aderiu ou não a algum programa social; e reduzir a dependência de carros-pipas quando, por algum motivo, a água da cisterna individual não for suficiente.

Seguindo esta linha, Oliveira (2013: 136) propõe como alternativa a "construção de uma segunda cisterna para as águas proveniente de carro-pipa”, para que não ocorra a mistura das águas. A construção de uma segunda cisterna poderá solucionar ao menos a questão da qualidade da água consumida.

É bom lembrar que as cisternas são políticas públicas que materializam a convivência com o Semiárido, e por isso, constituem-se em eficientes tecnologias sociais de acesso à água, apesar da necessidade dos reparos citados, eventualmente, ao garantir não apenas água, mas saúde e dignidade às pessoas que moram no $\mathrm{SAB}$, sobretudo, ao promover dinâmicas sociais de inclusão, empoderamento e vínculos de cooperação e cidadania na região (Costa \& Dias 2013).

\section{Considerações finais}

No decorrer deste trabalho, buscou-se analisar as transformações ocorridas na comunidade Carcaré após a chegada dos programas P1MC e do $\mathrm{P} 1+2$ da ASA. O estudo permitiu observar que diferentemente das outras políticas que vulgarmente tem sido destinadas à população do Semiárido, as tecnologias sociais de acesso à água da ASA representam progresso na concepção de convivência com o Semiárido, no qual um grupo social, que por anos foi excluído e marginalizado em decorrência de questões políticas e socioeconômicas, hoje caminha em direção a uma sociedade mais democrática, participativa e inclusiva, mesmo que ocorra em passos lentos.

As ações consolidadas pelo Programa social da ASA, como o fortalecimento da agricultura familiar, o domínio e apropriação das tecnologias sociais, autogestão de seus recursos hídricos e geração de renda são práticas desenvolvidas na comunidade que alteraram a dinâmica e a relação de homens e mulheres com o meio, comprovando a viabilidade de sua implantação e contribuindo com o paradigma da convivência com o Semiárido.

Com a leitura da realidade a partir das famílias que ali vivem, foi possível refletir sobre o papel desempenhado pelas tecnologias sociais de acesso à água na construção da autonomia das famílias da comunidade Carcaré em relação às políticas de combate à seca e como influenciaram o contexto o qual estão inseridas as famílias no campo.

As cisternas são tecnologias sociais simples que alcançaram a maior parte da população, cujos benefícios evidenciados neste estudo, demonstraram ser a principal referência de 
convivência com o Semiárido para os moradores da comunidade Carcaré, embora seja necessário e possível desenvolver outras tecnologias sociais e estratégias de convivência com o Semiárido, para que seu campo de visão não limite-se apenas ao uso de cisternas.

Apesar da importância que as tecnologias sociais de acesso à água desempenham, existem diversos desafios para consolidar uma concepção de sustentabilidade e convivência. Quando a água da cisterna não é suficiente para os períodos de estiagem surge questionamentos, como por exemplo: houve desvio de finalidade da água? A capacitação conseguiu mobilizar todo o público? A família entende que as cisternas devem ser utilizadas apenas como reservatório de água, independente de onde ela venha? Será que questões de saúde, mobilidade reduzida e grau de instrução influenciam essas práticas? A construção de uma segunda cisterna ou a adoção de outras tecnologias sociais de acesso à água reduzirá os efeitos decorrentes do desvio de finalidade de cisterna? Quais estratégias poderão ser adotadas em anos de baixa pluviosidade? Embora, não seja objetivo desta pesquisa, trata-se de situações emergentes que precisam ser pensadas, sobretudo, por poder auxiliar a repensar novas estratégias eficientes para os programas de acesso à água implantado pela ASA.

É necessário que o processo de armazenamento de água não se restrinja apenas às cisternas, mas que incorporem águas superficiais e subterrâneas, interligados a questão fundiária de acesso à terra, como forma de ruptura com a dependência política das classes dominante, que continuam a incorporar práticas do tradicional paradigma da seca, a denominada "indústria da seca".

Ressalta-se, também, a necessidade de investir em processos de formação na comunidade que possam discutir sobre estratégias sociais de acesso a água e terra, e que tais iniciativas formativas contemplem as necessidades das famílias, como forma de melhorar não só o acesso e gestão das águas, mas o fortalecimento da autonomia e convivência com a região semiárida.

Por fim, os dados desta pesquisa fornecem informações importantes para a compreensão da importância das tecnologias sociais de acesso à água para as comunidades rurais do Semiárido. Deste modo, espera-se que os subsídios deste trabalho orientem novos pesquisadores e despertem o interesse para realização de novas pesquisas, seguindo as múltiplas possibilidades, perspectivas e questionamento que podem surgir sobre o tema.

\section{Agradecimentos}

Aos avaliadores pelas críticas construtivas ao texto.

\section{Referências}

Abílio F.J. (2011) Educação Ambiental: conceitos, princípios e tendências (p. 97-137). In: Abílio F.J. (Orgs). Educação ambiental para o Semiárido. João Pessoa: Editora Universitária da UFPB. $582 \mathrm{p}$.

Alencar M.O., Justo W.R. \& Alves D.F. (2018) Os efeitos do programa "uma terra e duas águas (p1+2)" sobre a qualidade de vida do pequeno produtor rural do semiárido nordestino. Revista econômica do Nordeste, 49(1): 165-180.

Alves A.P. (2013) Convivência com o Semiárido (p. 35-37). In: Conti I.L. \& Schroeder E.O. (Orgs). Estratégias de Convivência com o Semiárido Brasileiro: Texto e Artigos de Alunos (as) Participantes. Brasília: Editora IABS. 212 p.

ASA (2019a) Articulação Semiárido Brasileira. Mapa de Tecnologias. Disponível em: http://www. asabrasil.org.br/mapatecnologias/\#. (acessado em 10/11/2019).

ASA (2019b) Programa Um milhão de Cisternas (P1MC). Disponível em: http://www.asabrasil.or g.br/acoes/p1mc. (acessado em 10/11/2019).

ASA (2019c) Programa Uma Terra e Duas Águas (P1+2). Disponível em: https://www.asabrasil.or g.br/acoes/p1-2\#categoria_img. (acessado em 10/11/2019). 
Arsky I.C. \& Santana V.L. (2013) Parâmetros de demanda hídrica no semiárido (p. 149-158). In: Conti I.L. \& Schroeder E.O. (Orgs). Convivência com o Semiárido Brasileiro: Autonomia e Protagonismo Social. Brasília: Editora IABS. 210 p.

Arsky I.C., Santana V.L. \& Pereira C.M. (2013) Acesso à água no semiárido: a água para o consumo humano (p. 139-148). In: Conti I.L. \& Schroeder E.O. (Orgs). Convivência com o Semiárido Brasileiro: Autonomia e Protagonismo Social. Brasília: Editora IABS. 210 p.

Baptista N.Q. (2011) Conhecendo e refletindo sobre o Semiárido e Agroecologia (p. 9-17). In: Santos B.M.C., Oliveira C.S., Lopes M.R., Carneiro V.M.O. \& Souza Z.L. (Orgs). Construindo Saberes para Educação Contextualizada. Bahia: Gráfica JB Ltda. 124 p.

Baptista N.Q. (2016) As Tecnologias Sociais e seu Papel na Transformação da Sociedade (p. 2941). In: Santos A.P., Cunha A.R.B.A., Denis A.A.C. \& Perez-Marin A.M.P. (Orgs). Vivências e Práticas Para Coabitação no Semiárido Brasileiro: Ensaios e Reflexões. Campina Grande: Instituto Nacional do Semiárido (INSA). 207 p.

Baptista N.Q. \& Campos C.H. (2013a) Possibilidades de construção de um modelo sustentável de desenvolvimento no semiárido (p. 59-72). In: Conti I.L. \& Schroeder E.O. (Orgs). Convivência com o Semiárido Brasileiro: Autonomia e Protagonismo Social. Brasília: Editora IABS. 210 p.

Baptista N.Q. \& Campos C.H. (2013b) Formação, organização e mobilização social no semiárido brasileiro (p. 73-82). In: Conti I.L. \& Schroeder E.O. (Orgs). Convivência com o Semiárido Brasileiro: Autonomia e Protagonismo Social. Brasília: Editora IABS. 210 p.

Baumgarten M. (2008) Ciência, tecnologia e desenvolvimento - redes e inovação social. Parcerias Estratégicas, 13(26): 101-123.

BRASIL (2017) Resolução No 115, de 23 de novembro de 2017. Aprova a Proposição no 113/2017, que acrescenta municípios a relação aprovada pela Resolução CONDEL n ${ }^{0}$ 107, e 27 de julho de 2017. Fortaleza: Ministério da Integração Nacional. Disponível em: http://sudene.gov.br/images/arquivos/conselhodeliberativo/resolucoes/resolucao115-23112017 -delimitacaodosemiarido.pdf (acessado em: 28/09/2020).

BRASIL (2018) Decreto de $\mathrm{N}^{\mathrm{o}}$ 9.606, de 10 de Dedembro de 2018. Regulamenta o Programa Nacional de Apoio à Captação de Água de Chuva e Outras Tecnologias Sociais de Acesso à Água - Programa Cisternas. Disponível em: http://www.planalto.gov.br/ccivil_03/_ato2015-2018/2018/decreto/D9606.htm (acessado em 18/11/2020).

Carlixto-Junior F. \& Silva A.C. (2016) Sustentabilidade e políticas públicas de convivência com o semiárido: um olhar sobre as tecnologias sociais no campo. Revista da Casa da Geografia de Sobral, 18(1): 44-62.

Costa A.B. \& Dias S.R.B. (2013) Estado e sociedade civil na implantação de políticas de cisternas (p. 33-64). In: Costa A.B. (Orgs). Tecnologia Social e Políticas Públicas. São Paulo: Instituto Pólis. 286 p.

Gerhardt T. E. \& Souza A.C. (2009) Aspectos teóricos e conceituais (p. 11-29). In: Gerhardt T.E. \& Silveira D.T. (Orgs). Métodos de pesquisa. Porto Alegre: Editora da UFRGS. 120 p.

Gil A.C. (2008) Métodos e técnicas de pesquisa social. $6^{\circ}$ edição. São Paulo: Atlas. 220 p.

Gomes A.F. \& Heller L. (2016) Acesso à água proporcionado pelo Programa de Formação e Mobilização Social para Convivência com o Semiárido: Um Milhão de Cisternas Rurais: combate à seca ou ruptura da vulnerabilidade? Engenharia Sanitária e Ambiental, 21(3): 623633. https://doi.org/10.1590/S1413-41522016128417

IBGE - Instituto Brasileiro de Geografia e Estatística (2010) Censo Demográfico. Disponível em: https:/cidades.ibge.gov.br/brasil/pb/sao-jose-da-lagoa tapada/pesquisa/23/27652?detalhes=true (acessado em 18/11/2020).

IBGE - Instituto Brasileiro de Geografia e Estatística (2017a) Regiões Geográficas. Disponível em: https://www.ibge.gov.br/apps/regioes_geograficas/ (acessado em 14/11/2020).

IBGE - Instituto Brasileiro de Geografia e Estatística (2017b) Produto Interno Bruto dos Municípios. Disponível em: https://cidades.ibge.gov.br/brasil/pb/sao-jose-da-lagoa-tapada/pesq uisa/38/46996 (acessado em: 28/09/2020). 
IBGE - Instituto Brasileiro de Geografia e Estatística (2017c) Censo Agropecuário. Disponível em: https://cidades.ibge.gov.br/brasil/pb/sao-jose-da-lagoa-tapada/pesquisa/24/76693 (acessado em: 20/06/2019).

INSA - Instituto Nacional do Semiárido (2017) Nova delimitação expande o semiárido até o Maranhão: 73 novos municípios foram incluídos. Disponível em: https://portal.insa.gov.br/not icias/1070-nova-delimitacao-expande-o-semiarido-ate-o-maranhao-73-novos-municipios-foramincluidos (acessado em: 16/11/2020).

Jesus V.M.B. \& Costa A.B (2013) Tecnologia social: breve referencial teórico e experiências ilustrativas (p. 17-32). In: Costa A.B. (Orgs). Tecnologia Social e Políticas Públicas. São Paulo: Instituto Pólis. 286 p.

Lakatos E.M. \& Marconi M.A. (2010) Fundamentos de metodologia científica. $5^{\circ}$ edição. São Paulo: Atlas. 310 p.

Malvezzi R. (2007) Semi-árido - uma visão holística. Brasília: Confea. 140 p.

Malvezzi R. (2012) Seca furiosa. Disponível em: http://www.acessodesterro.com/2012/04/secafuriosa-por-roberto-malvezzi.html (acessado em 21/09/2019).

Malvezzi R. (2016) Uma Conceituação Processual e Holística da Convivência com o Semiárido (p. 13-28). In: Santos A.P., Cunha A.R.B.A., Denis A.A.C. \& Perez-Marin A.M.P. (Orgs). Vivências e Práticas Para Coabitação no Semiárido Brasileiro: Ensaios e Reflexões. Campina Grande: Instituto Nacional do Semiárido (INSA). 207 p.

Melito L. (2020) Programa de cisternas enfrenta "seca" de recursos e fome bate à porta do semiárido. Disponível em: https:/www.brasildefato.com.br/2020/01/21/programa-de-cisternasenfrenta-seca-de-recursos-e-fome-bate-a-porta-do-semiarido (acessado em 18/11/2020).

Mota C.S. (2017) As cisternas como novos paradigmas para a convivência no semiárido: o caso da comunidade rural de Riacho da Arara, Cajazeiras - PB. Monografia (Graduação em Geografia). Universidade Federal de Campina Grande, Cajazeiras, Paraíba.

Oliveira D.B.S. (2013) O uso das tecnologias sociais hídricas na zona rural do semiárido paraibano: Entre o combate a seca e a convivência com o semiárido. Dissertação (Programa de Pós-Graduação em Geografia). Universidade Federal da Paraíba, João Pessoa, Paraíba.

Pereira E.S. (2013) Educação Contextualizada e Convivência com o Semiárido: lutas, conquistas e desafios (p. 97-108). In: Conti I.L. \& Schroeder E.O. (Orgs). Convivência com o Semiárido Brasileiro: Autonomia e Protagonismo Social. Brasília: Editora IABS. 210 p.

Pinto E.B. \& Lima M.J.A. (2008) O Programa de convivência com o semi-árido brasileiro e sua influência na mudança de hábitos e valores. Cadernos de Estudos Sociais, 24(1): 71-85.

PNUD - Programa das Nações Unidas para o Desenvolvimento (2013) Atlas do Desenvolvimento Humano no Brasil. Disponível em: https://www.br.undp.org/content/brazil/pt/home/idh0/ranki ngs/idhm-municipios-2010.html (acessado em: 15/06/2019).

Rocha J.C. (2013) Soberania e segurança alimentar no semiárido (p. 107-116). In: Conti I.L. \& Schroeder E.O. (Orgs). Convivência com o Semiárido Brasileiro: Autonomia e Protagonismo Social. Brasília: Editora IABS. 210 p.

Silva R.M.A. (2003) Entre dois paradigmas: combate a seca e convivência com o semi-árido. Sociedade e Estado, 18(1-2): 361-385. http://dx.doi.org/10.1590/S0102-69922003000100017

Silva R.M.A. (2006) Entre o combate à seca e a convivência com o semiárido: transições paradigmáticas e sustentabilidade do desenvolvimento. Tese (Programa de Pós-Graduação em Desenvolvimento Sustentável). Universidade de Brasília, Centro de Desenvolvimento Sustentável, Brasília.

Silva P.C.G., Moura M.S.B., Kiill L.H.P., Brito L.T.L., Pereira L.A., Sa I.B., Correira R.C., Teixeira A.H.C., Cunha T.J.F. \& Guimarães-Filho C. (2010) Caracterização do Semiárido brasileiro: fatores naturais e humanos (p. 18-48). In: Sa I.B. \& Silva P.C.G. (Eds). Semiárido brasileiro: pesquisa, desenvolvimento e inovação. Petrolina: Embrapa Semiárido. 402 p.

Silva M.L.M., Rodrigues A.O. \& Silva S.L. (2013) Transformações e protagonismo social no semiárido (p. 38-58). In: Conti I.L. \& Schroeder E.O. (Orgs). Estratégias de Convivência com o Semiárido Brasileiro: Texto e Artigos de Alunos (as) Participantes. Brasília: Editora IABS. 212 p. 
Silva S.D., Medeiros V.P. \& Silva A.B. (2016) Tecnologias sociais hídricas para convivência com o semiárido: o caso de um assentamento rural do município de Cabaceiras - PB. Holos, 1: 295309. https://doi.org/10.15628/holos.2016.3312

Suassuna J. (2007) Semi-árido: Prosposta de convivência com a seca. Caderno de Estudos Sociais, 23(1-2): 135-148.

SUDENE - Superintendência do Desenvolvimento do Nordeste (2017) Mapa de delimitação do Semiárido. Disponível em: http://antigo.sudene.gov.br/images/arquivos/semiarido/arquivos/m apa-semiarido-1262municipios-Sudene.pdf (acessado em 14/11/2020).

Tomaz B.M. (2017) Turismo e sustentabilidade: um estudo sobre os recursos turísticos potenciais na serra de Santa Catarina, São José da Lagoa Tapada-PB. Monografia (Graduação em Geografia). Universidade Federal de Campina Grande, Cajazeiras, Paraíba.

Ventura A.C., Andrade J.C.S. \& Garcia L.F. (2014) Tecnologias sociais de convivência com o semiárido como estratégia de mitigação/adaptação às mudanças climáticas no Brasil. Astrolabio, 12: 43-72. 